\title{
The relationship between financial innovation theory and financial supervision evolution
}

\author{
Yao Cheng \\ International Business School \\ Beijing Language and Culture University \\ Beijing, 100085 China
}

\begin{abstract}
Since the late 1990 s, the development of financial innovation theory and practice has proved that financial risk is also a "resource" available, and there are also "resource allocation" of risks. Marketing allocation of risks can save social capital resources. With the intensification of information technology and competition, social and economic functions of financial institutions gradually "evolved" into a dual role as the main intermediary for allocation of financial resources and the body of allocation of financial risks. Accordingly, the marketizations of financial risk allocation become a useful supplement to financial regulation, and financial innovation has become an important means of providing financial regulatory efficiency. China's financial regulatory system should pay attention to the complementary relationship between financial innovation and financial supervision, regulate and encourage the development of financial innovation.
\end{abstract}

Keywords-Financial innovation, financial regulation, development

\section{INTRODUCTION}

Since the 1950s, a wave of financial innovation rose in Western countries, and evolved into globalization. The financial innovation has brought about the reform of the traditional business of financial institutions, blurred the boundaries of various financial institutions, and intensified competition in the financial sector, and promoted globalization and liberalization of financial business. Financial innovation also greatly

Improved the efficiency of allocation of scarce financial resources worldwide, greatly reduced the cost of borrowing funds, promoted financial deepening the development, and brought new challenges to the financial regulation. It also attracted the attention of many scholars; they put forward financial innovation theories from different views.

\section{THE CONNOT ATION OF FINANCIAL INNOVATION}

Financial Innovation (Financial Innovation) is the logical starting point for defining the meaning of financial innovation theory. "Innovation" (Innovation) was first used by Schumpeter in his book Theory of Economic Development. He proposed the so-called innovation is to create a new production function, namely entrepreneurs combine new factors of production and production conditions into the activities of the new system of social production. The new combination includes the following things: the introduction of new products, introduction of new technology, opening up new markets, controlling new sources of raw materials, achieving a new combination of enterprises. Schumpeter believed that innovation was the core concepts to understand the capitalist system and its development. Innovation is the process of economic development, the reasons for economic development and also the nature of economic development.

With a Western wave of financial innovation, the concept of financial innovation has come into being. Domestic and foreign scholars have the following statements about the connotation of financial innovation: domestic famous economists argue that financial innovation is to create a new production function in the financial sector, to combine a variety of new financial factors, to pursue profit opportunities and therefore it is a market reform. It includes a series of new things in the financial system and financial markets, including new financial instruments, the new financing, new financial markets, new means of payment and settlement, the new forms of financial organization and management etc. In addition, some scholars believe that financial innovation is the "breakthrough" of the traditional business situation in financial business for many years to reform obviously in terms of innovative financial instruments, financial way, financial technology, financial institutions, financial markets, etc. A Journal published in New York defined financial innovation as " a payment system to promote or weaken the function of bank and other financial institutions as an intermediary" and pointed out four main aspects: technological innovation, risk transferring innovation, credit creation innovation and production stock rights innovation. Ten central banks research team prepared a research report in 1986 published in recent years and it gave the definition of financial innovation. The financial innovation is to have several financial instruments of characteristics re- combined to create new financial instruments. Financial innovation is a way of financial development. It appears as a new combination of financial elements to achieve financial superstructure volume expansion. Despite the expression of different definitions of 
financial innovation, its essence is the same. According to the previous contents we can be put financial innovation into the market innovation and system innovation. Market innovation includes financial instruments innovation, business methods innovation, and financial institutions and organizations innovation. System innovation is the government-led reform of the financial system, such as deregulation measures and arrangements for strengthening the supervision. Market innovation always precedes system innovation. System innovation makes the results of market innovation standardized and legalized.

Financial innovation began in the 1950s and constantly shows booming trend up until now. What is it that makes financial innovation have so vitality? What is the driving force of financial innovation? In order to theoretically explore driving force of financial innovation, Western scholars have done a lot of research about the phenomenon of financial innovation, and have developed different theories and ideas, thus formed different contemporary theories of financial innovation.

\section{MOTIVATION THEORY OF FINANCIAL INNOVATION}

In the 1970 s financial innovation largely appeared, scholars studied on the causes of these financial innovations from different angles, and formed a relatively systematic financial innovation motivation theory. Summarizing the characteristics of these theories and studying them co mbined with the experience of Western countries, the motivation of financial innovation has two aspects: First, the active innovation of innovators in the pursuit of profit, namely the innovation to conform to the needs; Second, passive innovation of innovation body to avoid adverse impacts of the environment, namely the innovation to conform to the supply. If we say the former is for development which is an offensive innovation, while the latter is for survival which is a defensive innovation. In the specific innovation activities, it can be divided into motivation adapting to the needs, adapting to supply and to evade the regulation. To circumvent regulation is a composite form of the first two.

\section{A. Motivation to conform to the needs}

Conforming to the needs means that with the financial development as well as changes in the economic environment, economic agents have some new financial demands. In order to meet these new requirements to obtain profits, the innovation is carried out. These new requirements include demands for financial investment products of people of wealth growth, for preventing moral hazard and adverse selection produced by asymmetry financial market information, and for risk prevention due to fluctuations in interest rates and exchange rate.

\section{B. Motivation to conform to supply}

Motivation conforming to supply means that due to the new trading technology, the emergence of business models and management philosophy, its financial sector to be applies financial innovation to reduce the cost. There are many factors to reduce the cost of the financial sector including a new science and technology, the emergence of new trading methods, new business models and applications of new management philosophy.

\section{Motivation to circumvent regulation}

Motivation to circumvent regulation means that due to the stricter regulation in the financial industry than other industries, when certain constraints can reasonably be broken and can bring benefits, financial innovation occurs. Rules of government regulation have become an important driving force of innovation. Scholars study from evading government regulation, getting rid of internal and external constraints and interaction of systems. Many forms of government regulation are substantially equal to the implicit tax, hindering the profit opportunities of financial institutions and the use of outside activities. So financial institutions escape govemment control through innovation, and when financial innovation may endanger financial stability and monetary policy, financial authorities will tighten control, and the new regulation will lead to new innovation. They form a mutually reinforcing process.

\section{RELATIONSHIP BETWEEN FINANCIAL INNOVATION AND FINANCIAL SUPERVISION}

In the risk allocation markets, financial innovation and financial supervision has evolved into a complementary relationship rather than a contradictory: First, modern financial regulation is based on risk, and its fundamental point is to make the financial risk controlled in an appropriate lever through external intervention. Development of financial innovation promotes the formation of risk allocation market. The uses of market-based tools objectively improve the level of risk management. The restrictions of market become the most beneficial supplement to risk regulation. Second, the depth and breadth of financial innovation depend on the degree of development of the risk allocation market. Financial institutions can shorten time to market evolution, regulate market behavior and reduce transaction costs through external intervention, thereby to promote the development of risk allocation market and protect normal operation of the market.

\section{THE IMPACT OF FINANCIAL INNOVATION ON THE FINANCIAL MANAGEMENT}

The impact of financial Innovation on the financial management evolution Development of financial innovation theory, the evolution of financial organizations function, the relationship between financial innovation and financial supervision are not only the problems to study and discuss in the financial innovation theory, but also problems of the design and reforming process of financial regulatory system, especially for countries with economies in transition. In the past they took "strengthen supervision" as the subject of financial regulation reform, ignoring the close coordination between external regulation and market discipline, hoping to promote financial innovation by the use of regulatory dialectic. It has taken the road of "to block water ".the actual level of regulation is difficult to get a substantial improvement in the ability of financial innovation potential will be suppressed. China is a country with economies in 
transition and its financial innovation is in the ascending period. In the financial regulatory reform process, we should pay particular attention to preventing the mistakes due to theoretical misunderstanding.

First, many problems exist in China's financial system; it requires the use of financial innovation instruments. Financial innovation is a long continuous process. From the perspective of the development of China's financial industry and to enrich financial products, to improve the overall operation and profitability of financial institutions are the basis to improve the international competitiveness of China's financial industry, and to protect the healthy development of the financial sector. China's current financial management system is still separate operation and regulation. The abolition of restrictions on operation will take time. Under the established legal system and management system, the improvement of the level of diverse management and profitability of commercial banks and other financial institutions can only rely on financial innovation. From the perspective of the stability of China's financial industry, the reasons for the formation of a large number of nonperforming assets in the financial system are both out of policy and operational aspects. It is also the result of contradictory interests in specific institutional context. Due to the formation mechanism and other aspects of Chinese characteristics it is hard to employ foreign centralized way to solve them.

Second, the important role of financial innovation requires China's financial regulatory system should encourage rather than restrict financial innovation, to relax rather than strengthen controls. We should abandon onesided regulatory reform ideas which are in order to strengthen the supervision. We should make clear purpose and scope of financial regulation, give full play to the role of financial innovation and risk allocation through the formation of market-based risk management instruments as soon as possible. Due to the impact of history and culture, our current social system puts one-sided emphasis on strengthening supervision, still adheres to strict separate operation and separate supervision and simply expands the power of administrative supervision which may not really improve the actual level of risk manage ment systems. Maybe, due to the impact of interests, the subdivision and strengthening of regulatory powers may lead to the rapid rise in the cost of regulatory coordination and the decline of comprehensive regulatory efficiency and effectiveness. Meanwhile, in any society, the power of financial supervision is positively correlated with financial rentseeking behavior and arbitrariness of financial management. Whether political or economic rent-seeking behaviors, once intensified by incidental factors, it will form a financial management system which only focuses on the local. If this phenomenon becomes reality, the financial system will still maintain development, but this development will become regressive improvements that could eventually lead to the widening of disparities in levels of development between China and the international or even decline. On the contrary, according to the modern theory of financial innovation and redefinition of the relationship between financial innovation and regulation, actively cultivating the domestic risk allocation market through financial instruments, financial transactions and other innovation is conducive to the transferring of administrated regulatory to external regulatory. By combining the use of market forces, it can supplement and improve the deficiencies of the existing regulatory system, and gradually construct the foundation for long-term regulatory system. Second, it helps the commercial banks to improve their product mix, enrich social financial investment instruments and gradually change our long-standing abnormal expansion of deposit and loan business situation. Third, financial regulation and financial innovation complement each other. Regulation is an insurance of innovation. Innovation is an important way to save resources and improve regulatory efficiency. We should take advantage of market-based instruments to manage risk and improve regulatory standards. In terms of regulatory systems and policies, we should deal with standardizing trading tools, market and trade body. First, we should strictly regulate the financial management procedures and systems of innovation. And we should also regulate design, nature, marketing and management of products, and statistical reports of legal relationship etc. We should gradually relax main financial innovation trading restrictions to improve the efficiency of risk allocation.

\section{REFERENCES}

[1] Wang Daxian, Sunaihong. Development trend of China's financial innovation and its impact on financial development and financial regulation [J]. Economist, 2003,01:246 -247.

[2] Yoon Yong. Development of financial innovation and financial supervision system theory of evolution [J]. Financial Research,2005,03:7 - 15 .

[3] Zheng Aimin. Innovation and development of China's financial trends and regulatory research [D]. Hunan University, 2001.

[4] Chen Zekui. Structure of financial regulation studies [D]. Xiangtan University, 2005.

[5] Fuxing Kai. China Banking Regulatory optimal policy choice [D]. Foreign Economic and Trade University, 2006.

[6] Zhoujun. China's financial regulatory reform early on [D]. Capital University of Economics and Business, 2006.

[7] Zhang Bin. Patterns in China's financial supervision under Combined Selection [D]. Capital University of Economics and Business, 2006.

[8] Liu Chunxiang. Financial innovation process and its economic analysis [D]. Xiangtan University, 2002.

[9] Luo Rong. Comparative study [D] financial regulatory system model. Xiangtan University, 2002.

[10] Li Jun. Organizational structure of financial regulation studies [D]. Xiangt an University, 2003. 